\title{
UMA ESTÓRIA PARA A HISTÓRIA
}

\author{
Goffredo Telles Junior \\ Professor Catedrático aposentado da Faculdade de Direito da \\ Universidade de São Paulo
}

Estávamos em 1977. Vivíamos o $13^{\circ}$ ano de chumbo, em plena ditadura militar.

Havia em mim um sonho. Um sonho? O que em mim fervilhava era muito mais do que um sonho. Era um almejo ardente, um anhelo dominante. Era uma idéia arrebatadora. Era um projeto: o projeto de uma proclamação desassombrada incontido desabafo de minha alma, reflexo da alma flagelada de meu País. Era uma conjectura: a conjectura de um manifesto revolucionário brado carismático por liberdade e pelo Estado de Direito.

Das Arcadas do Largo de São Francisco, do "Território Livre" da Academia de Direito de São Paulo, eu queria dirigir a todos os brasileiros minha mensagem de aniversário uma alocução veemente, que fosse uma Proclamação de Princípios de nossas convicções políticas.

Na Academia, éramos herdeiros de um patrimônio cultural, recebido de nossos maiores. Ao ensejo do Sesquicentenário dos Cursos Jurídicos no Brasil, eu ansiava por dar o testemunho para as gerações futuras de que os ideais de Liberdade e Justiça, apesar das vicissitudes daquela hora, viviam e atuavam, então como sempre, no espírito vigilante das Arcadas.

O manifesto, que então irrompia em mim, não teria a pretensão de enunciar novidade. Ele nada mais diria do que aquilo que, de uma ou outra maneira, vinha sendo ensinado, ano após ano, nos cursos normais das faculdades de Direito de meu País. Mas seria uma proclamação vibrante de nossa fidelidade aos princípios fundadores da ordem jurídica democrática. Seria a demonstração viva de nossa determinação de luta, contra a ditadura e pela volta do Estado de Direito.

Seria o manifesto de nossas convicções.

Nós estávamos convictos de que a fonte genuina da ordem pública não era a Força, mas o Poder. Para nossa consciência jurídica, o Poder emana do povo; era produto da manifestação popular. A Força era outra cousa. Era a imposição das 
armas. A Força não deveria nunca ser mais do que instrumento a serviço do Poder. Nós denunciávamos como ilegítimo todo Governo fundado na Força. Legítimo somente o era o Governo que fosse órgão do Poder.

Para nós, ilegítimo era o Governo cheio de Força e vazio de Poder.

Reconhecíamos que o Chefe do Governo era o mais alto funcionário nos quadros administrativos da Nação. Mas negávamos que ele fosse o mais alto Poder de um País. Acima dele, reinava o Poder de uma idéia: reinava o Poder das convicções que inspiravam as linhas mestras da Política nacional. Reinava o senso grave da Ordem, que se achava definido na Constituição.

Proclamávamos a soberania da Constituição.

Sustentávamos que nenhum ato legislativo podia ser tido como lei superior à Constituição.

Uma lei só era válida se a sua elaboração obedecesse aos preceitos constitucionais, ou seja, às normas do processo legislativo. Ela só era válida se suas disposições não se opusessem ao pensamento da Constituição.

Observávamos que a Constituição também era uma lei. Mas era a Lei Magna. O que, antes de tudo, a distinguia nitidamente das outras leis era que sua elaboração e seu mérito não se submetiam a disposições de nenhuma lei superior a ela. Aliás, não podíamos admitir como legítima lei nenhuma que lhe fosse superior.

Afirmávamos que a fonte legítima da Constituição era o Povo.

Sustentávamos, também, que só o Povo, por meio de seus representantes no Congresso Nacional, tinha competência para emendar a Constituição. Sustentávamos que as emendas na Constituição não se podiam fazer como se faziam as alterações na legislação ordinária. Na Constituição, as emendas precisavam ser apresentadas, processadas e aprovadas em conformidade com preceitos especiais, que a própria Constituição estabelecia, preceitos estes que tinham por fim conferir à Lei Magna do Povo uma estabilidade maior do que a das outras leis.

Considerávamos ilegítimas as emendas na Constituição que não fossem feitas pelo Parlamento, que não obedecessem, no encaminhamento, na votação e na promulgação, a todas as formalidades do rito que a própria Carta Magna prefixava, em disposições expressas.

Para nós, o exercício do Poder Constituinte, por autoridade que não fosse o Povo, configurava usurpação de poder político. 
Se ao Poder Executivo fosse facultado reformar a Constituição, ou submetê-la a uma legislação discricionária, a Constituição perderia, precisamente, seu caráter constitucional, e passaria a ser um farrapo de papel.

No meu idealizado Manifesto eu proclamaria: "O Estado legítimo é o Estado de Direito, e o Estado de Direito é o Estado Constitucional"

Eu diria que o Estado de Direito é o Estado que se submete ao princípio de que governos e governantes devem obediência à Constituição.

Bem simples se nos afigurava este princípio, mas luminoso, porque se ergue, como barreira providencial, contra o arbítrio de vetustos e renitentes absolutismos. A ele as instituições políticas das Nações somente chegaram após um longo e acidentado percurso na História da Civilização. Sem exagero, poder-se-ia dizer que a consagração desse princípio representava uma das mais altas conquistas da cultura, na área da Política e da Ciência do Estado.

Eu lembraria, em meu Manifesto, que, nos países em que a cultura política já organizou o Estado de Direito, a insólita implantação do Estado de Fato ou de Exceção - do Estado em que o presidente da República volta a ser o monarca lege solutus constituía um violento retrocesso no caminho da cultura. Uma vez reimplantado o Estado de Fato, a Força tornaria a governar, destronando o Poder. Então, bens supremos do espírito humano, somente alcançados após árdua caminhada da inteligência, em séculos de História, seriam simplesmente ignorados. Os valores mais altos da Justiça, os direitos mais sagrados dos homens, os processos mais elementares de defesa do que é de cada um, seriam vilipendiados, ridicularizados e até ignorados, como se nunca tivessem existido.

O que os Estados de Fato, Estados Policiais, Estados de Exceção, Sistemas de Força apregoavam era que havia Direitos que deviam ser suprimidos ou cerceados, para tornar possivel a consecução dos ideais desses próprios Estados e Sistemas.

Em lugar dos Direitos Humanos, a que se refere a Declaração Universal das Nações Unidas, aprovada em 1948; em lugar do habeas corpus, em lugar do direito dos cidadãos de eleger seus governantes, esses Estados e Sistemas colocariam o que chamam de Segurança Nacional e Desenvolvimento Econômico.

Com as tenebrosas experiências dos Estados Totalitários europeus, nos quais o lema era, e sempre foi, Segurança e Desenvolvimento, aprendemos uma dura lição. Aprendemos definitivamente que, fora do Estado de Direito, o referido binômio pode não passar de uma cilada. Fora do Estado de Direito, a Segurança, 
com seus órgãos de terror, é o caminho da tortura e do aviltamento humano; e 0 Desenvolvimento, com o malabarismo de seus cálculos, é a preparação para o descalabro econômico, para a miséria e a ruína.

No meu Manifesto, eu afirmaria que nós não nos deixaríamos seduzir pelo canto das sereias de quaisquer Estados de Fato. Não nos iludiriamos com a pregação da Segurança e do Desenvolvimento.

Eu afirmaria que o binômio Segurança e Desenvolvimento não tem o condão de transformar uma ditadura numa Democracia, um Estado de Fato num Estado de Direito.

Eu declararia falsa a vulgar afirmação de que o Estado de Direito e a Democracia são "a sobremesa do desenvolvimento econômico" Eu lembraria que desenvolvimentos econômicos se fazem, às vezes, nas mais hediondas ditaduras.

Eu proclamaria que nenhum País deve esperar por seu desenvolvimento econômico, para depois implantar o Estado de Direito. Advertiria que os Sistemas, nos Estados de Fato, ficam permanentemente à espera de um maior desenvolvimento econômico, para nunca implantar o Estado de Direito.

O que nós sustentávamos nós, democratas era que o Estado de Direito é sempre primeiro, porque primeiro estavam os direitos e a segurança da pessoa humana. Nenhuma idéia de Segurança Nacional e de Desenvolvimento Econômico preponderava sobre a idéia de que o Estado existe para servir o homem.

Estávamos convictos de que a segurança dos direitos da pessoa humana era a primeira providência para garantir o verdadeiro desenvolvimento de uma Nação.

Nós queríamos segurança e desenvolvimento. Mas queríamos segurança e desenvolvimento dentro do Estado de Direito.

Em meio da treva cultural do Estado de Fato, eu diria em meu Manifesto que a chama acesa da consciência jurídica não cessava de reconhecer que não existiam, para Estado nenhum, ideais mais altos do que os da Liberdade e da Justiça.

No meu Manifesto, eu sustentaria que o Brasil dos ditadores não era o nosso Brasil. No Brasil dos ditadores, a sociedade civil estava banida da vida política da Nação. Pelos chefes do Sistema, a sociedade civil era tratada como se fosse um confuso conglomerado de ineptos, sem discernimento e sem critério, aventureiros e aproveitadores, incapazes para a vida pública, destituídos de senso moral e de idealismo cívico como se fosse uma desordenada multidão de ovelhas 
negras, que precisava ser continuamente contida e sempre tangida pela inteligência soberara do sábio tutor da Nação.

No Brasil dos anos de chumbo, o Poder Executivo, por meio de atos arbitrários, declarara a incapacidade da sociedade civil, e decretara a sua interdição.

Pois eu queria proclamar, num claro Manifesto, a ilegitimidade de todo sistema político em que abismos se abrem entre a sociedade civil e o Governo.

Nós chamávamos de ditadura o regime em que o Governo está separado da sociedade civil. Ditadura era o regime em que a sociedade civil não elege seus Governantes e não participa do Governo. Ditadura era o regime em que o Governo governa sem o Povo. Ditadura era o regime em que o Poder não vem do Povo. Ditadura era o regime que castiga seus adversários pelo fato de serem adversários.

Ditadura era o regime que governa para nós, mas sem nós.

Eu diria no meu Manifesto que nós nos recusávamos, de uma vez por todas, a aceitar a falsificação dos conceitos. Para nós, a ditadura se chama ditadura, e a Democracia se chama Democracia.

Os governantes que davam o nome de Democracia à ditadura nunca nos enganaram e não nos enganarão. Nós sabíamos que eles estavam atirando, sobre os ombros do povo, um manto de irrisão.

Em abril de 1977. a Congregação dos Professores da Faculdade de Direito de Bauru me convidou para proferir, naquela Escola, uma aula sobre os Direitos Humanos e sobre a ordem jurídica numa Democracia. Atendendo ao solicitado, ali pronunciei, em 19 de abril, uma dissertação sobre " $O$ Legal e $o$ Legítimo, no Direito do Brasil atual" À luz desses dois conceitos, conduzi minha dissertação para a análise da representação política na obra legislativa, e para a crítica das aberrações da ditadura. Lembro-me de haver dito que "os Atos Institucionais eram o pé-de-cabra para 0 arrombamento das estruturas constitucionais da Nação"

Em princípios de maio, Maria Eugenia e eu recebemos, de surpresa, em nosso escritório, a encantadora visita de Samuel Wainer.

Eu o conhecia pessoalmente, desde meu tempo de deputado. Em verdade, eu o conhecia desde o tempo do Estado Novo, de Getúlio Vargas, ocasião em que ele criara, com o patrocínio do presidente, o grande jornal popular Última 
Hora. De longe, acompanhei sua trajetória de jornalista. Eu o tinha como um dos maiores repórteres de toda a História do Brasil.

Em novembro de 1975, Wainer fundou o semanário Aqui São Paulo, a cuja consolidação ele vinha dedicando o melhor de seus dias. Foi em nome desse jornal que ele veio conversar conosco.

O que ele queria, fundamentalmente, era inteirar-se dos motivos verdadeiros, do autêntico sentido da sublevação dos estudantes em nossa terra. Ele queria certificar-se das idéias da mocidade, e da revolução institucional que os estudantes desejavam. Bem informado sobre a atuação da Academia do Largo de São Francisco, disse-me que ele desejava conhecer a minha interpretação dos fatos, e solicitou-me uma completa e sincera entrevista, sobre o momentoso assunto.

Duas vezes, Wainer voltou ao nosso escritório, e eu the concedi uma longa entrevista, que ele publicou, com grande destaque, em seu vibrante semanário, na edição do dia 18 de maio de 1977.

Por coincidência, nesse mesmo dia 18 , a partir das dez horas da noite, a Polícia cercou a Cidade Universitária da USP o Largo de São Francisco e as áreas circunvizinhas da Pontifícia Universidade Católica. O objetivo dessa operação era impedir as manifestações programadas para o dia seguinte.

Estive no nosso Largo, ao fim da tarde. O Centro Acadêmico XI de Agosto havia planejado uma Noite de Vigília, na Faculdade de Direito, como preparação do Dia Nacional de Protesto. Lembro-me de meu desconsolo, ao encontrar fechadas as portas de minha Faculdade. A medida inusitada havia sido ordenada pelo diretor, de acordo com a advertência do Sr. Erasmo Dias, secretário da Segurança.

Em pleno Largo, diante do portão trancado, eu disse aos jornalistas: "Quero deixar claro que sempre estarei ao lado daqueles que batalham pelo Estado de Direito. Eu gostaria de ver a volta de meu País à Democracia. Estou com os estudantes. $O$ que os estudantes querem é o respeito à Constituição; é o predomínio da lei, do Direito e da Justiça. O que eles querem é simplesmente a ordem, mas a ordem no Estado de Direito. Para eles, os subversivos são, precisamente, aqueles que violam a Constituição"

Os jornais do dia 19 publicaram as minhas declaraçōes. Publicaram, igualmente, as palavras de Dom Paulo Evaristo Arns, pronunciadas logo após a missa em comemoração do Dia Mundial das Comunicações Sociais: Acredito que todo brasileiro de bom senso" disse o cardeal "defenda os quatro pontos cardiais 
do movimento estudantil que são: libertação dos colegas e operários presos, fim das torturas e prisões arbitrárias, anistia geral e liberdades democráticas"

Sobre o aparato de guerra, exibido pelo Governo, naquela noite e no dia seguinte, para impedir as manifestações dos estudantes, vários deputados se pronunciaram com indignação.

Meu amigo Israel Dias Novaes, deputado da bancada oposicionista de São Paulo, disse: "Causa espanto que o simples anúncio da concentração de estudantes alarme o Poder e o ponha em pé-de-guerra, com a mobilização de policiais militares, tanques e caminhões blindados"

O deputado Airton Soares afirmou: "Os manifestantes universitários têm o direito de se reunir em praça pública, democrática e pacificamente, e de exibir faixas e cartazes que reproduzam os motivos de sua manifestação e as suas reivindicações"

Odacyr Klein, deputado gaúcho, observou: "Efetivamente, parece que o Governo não entende a Nação. Ele quer ser o dono da verdade. Na sua concepção, todos que a ele se oponham são inimigos do Brasil, elementos radicais da desordem"

Naquela noite de 19 de maio, os senadores Paulo Brossard e Teotonio Vilela vieram à Faculdade, e ali pronunciaram luminosas conferências.

Revendo as anotações de meu canhenho, recordo que repórteres do Jornal do Brasil estiveram no meu escritório várias vezes, nos dias subseqüentes. Conservo em arquivo as entrevistas concedidas. E verifico que, instado pelos jornalistas, cheguei a lhes confessar, nessa ocasião, o sonho de meu Manifesto à Nação, em defesa das liberdades democráticas e do ideal de convocação da Assembléia Nacional Constituinte, para a restauração do Estado de Direito em meu País.

No dia 27 de maio, à noite, recebi, por telefone, uma notícia inesperada e grata. Fui informado de que o Conselho Seccional da OAB havia aprovado, na reunião da tarde, um voto de louvor aos professores Dalmo de Abreu Dallari, Miguel Reale Junior e a mim, "por tudo que esses mestres têm feito em favor da livre manifestação do pensamento e da Democracia"

$\mathrm{O}$ voto de apoio e solidariedade, declarado por meus colegas da Ordem quero dizê-lo agora, com franqueza calhou, de fato, naquela hora de riscos e insegurança. Fez-me grande bem, causou-me alegria, e muito penhorado fiquei pela manifestação. 
Nesse mesmo dia 27. a Nação havia sofrido mais um golpe da ditadura. O ministro da Justiça, em Portaria publicada no Diário Oficial, submeteu toda a futura importação de livros e periódicos à censura prévia do Departamento da Polícia Federal. Somente poderiam entrar no Brasil decretava a Portaria aquelas obras que "não fossem ofensivas à moral e aos bons costumes, ou à ordem pública"

O absurdo, o surrealismo, o arbítrio dessa medida causaram indignação e revolta, em todos os meios intelectuais do País. A Portaria fecha as janelas da dinâmica do conhecimento, que não tem fronteiras nacionais" escreveu a professora Cremilda Medina, em longo artigo, no jornal $O$ Estado de $S$. Paulo. Os jornais, o rádio, a TV. todos os meios de comunicação, numa impressionante unanimidade, revelaram a inconformação e o protesto dos que eram responsáveis pela difusão da cultura no Brasil.

Manifestaram-se imediatamente contra 0 ato obsolescente $e$ atrabiliário da ditadura os professores Antonio Candido _ Octavio Ianni (da Faculdade de Filosofia, Letras e Ciências Humanas), Rui Aguiar da Silva Leme (da Faculdade de Economia), Cândido Procópio (do Centro Brasileiro de Análise e Planejamento-CEBRAP), Sérgio Buarque de Holanda (da Faculdade de História) e muitos outros.

Os reitores da USP e da PUC - professores Orlando Paiva e Nadir Kfouri - envidaram esforços para livrar os professores, os Departamentos e os estudantes de suas Universidades dos rigores da Portaria. Obviamente, nada conseguiram.

O professor Antonio Cândido lançou a pergunta: "Qual a qualificação desses elementos da polícia para discriminar as obras que podem e as que não podem ingressar no País?"

A professora Nadir Kfouri afirmou: "Em principio, a censura parte do princípio da menoridade de um povo. (...) Não consigo imaginar como um censor possa ter mais discernimento que o cientista, o jurista, o poeta ou o artista"

O professor Cândido Procópio disse que, no seu entender, "aquela censura configurava, de forma flagrante, a tutela que o Estado queria exercer sobre uma sociedade considerada mentecapta, incapaz de se gerir, incapaz de optar por caminhos morais e intelectuais"

Estávamos mergulhados nessa onda de desgosto, quando Maria Eugenia e eu fomos convidados para um almoço. 
O bom telefonema do amigo Flavio Bierrenbach nos causou dois sentimentos: o primeiro, de satisfação; o segundo, de curiosidade. Pressentimos que algo se estava tramando. Flavio informou que ele falava, naquele momento, em nome de um grupo de colegas, mas se escusou, delicadamente, de revelar o motivo do almoço. Devo confessar que ficamos intrigados, com o tom de mistério que marcou o amável convite.

O almoço se realizou no restaurante do Círculo Italiano, no Edifício Itália, da Avenida São Luiz. Dela participaram cinco advogados: Flavio Bierrenbach, José Carlos Dias, Almino Affonso, Maria Eugenia e eu. A refeição transcorreu normalmente, como acontece nas reuniões de velhos amigos, colegas de profissão, que marcaram encontro, para matar saudades, em torno da mesa, ao meio dia.

Nada de novo, nada, nada se disse, nada que, de qualquer maneira, pudesse aplacar minha curiosidade até a hora da sobremesa, quando José Carlos Dias tomou um ar solene, pediu a atenção de todos, e declarou que ele e seus dois colegas, Flavio e Almino, ali estavam em missão.

Senti o coração bater no peito.

Disse José Carlos que um grupo de advogados filhos da Academia do Largo de São Francisco havia tomado a deliberação de deixar, num documento sacramentado, a expressão de seu repúdio ao regime de arbítrio e prepotência, que, durante quatorze anos, vinha infelicitando a Nação. Formados nas tradições das Arcadas, esses colegas queriam tornar impossivel a suposição de que seu silêncio sobre a ditadura pudesse algum dia ser interpretado como conivência com o absolutismo. Ao ensejo do Sesquicentenário da Academia, o que queriam era proclamar, numa inequívoca Mensagem aos brasileiros, sua inabalável fidelidade aos ideais da Liberdade, da Democracia e do Estado de Direito. E, por intermédio da embaixada, que ali se encontrava, em torno daquela mesa, vinham solicitar que eu redigisse o documento.

Que emoção, meu Deus! Que enorme emoção se apossou de mim, ao ouvir essas palavras! Que emoção senti, ao tomar ciência de que os filhos da Academia ansiavam por um Manifesto de nossas convicções! Que sobressalto d'alma experimentei, ao receber a incumbência que acabava de me ser dada! Aquele pedido se casava, maravilhosamente, com o projeto que fervilhava em meu espírito. Isto, informei com calor, aos três amigos. E acrescentei que aquela obra, por nós idealizada, eu me comprometia a elaborar, com todas as veras de meu ser. 
Flavio Bierrenbach nos comunicou que, embora não presentes ao almoço, também pertenciam à embaixada os colegas Ignácio Botelho de Mesquita, José Gregori e Cantidio Salvador Filardi. Nesse grupo, incluiu-se, dias depois, meu amigo de todos os tempos, André Franco Montoro. Ao saber do projeto, ele imediatamente se pôs em contato comigo, fazendo preciosas sugestões para o nosso Manifesto.

O MDB (Movimento Democrático Brasileiro), o grande Partido da oposição, realizava, naquela ocasião, um "Ciclo de Jornadas Democráticas" Deste certame, participei em 3 de junho, com uma conferência intitulada "Restauração do Estado de Direito" Lembro-me de haver dito, nesse pronunciamento: "Glória nossa é ser chamado de subversivos e desordeiros, pois assim é que são apelidados os defensores da ordem constitucional e do Estado de Direito. Grande ironia era chamar de defensores da ordem precisamente aqueles que violam a Constituição"

Em seu número de 6 de junho de 1977. a revista Visão, numa vasta reportagem, reproduziu algumas de minhas idéias sobre a situação política brasileira.

Naquele dia, precisamente, compareci no Centro de Atualização Cultural, a convite de sua diretora, a professora Maria Helena Gouveia, entidade onde a reportagem da Visão foi muito comentada, mas onde fiz uma exposição sobre outro assunto. Discorri sobre 'As molas do comportamento humano, à luz das últimas descobertas da Biologia"

No dia seguinte, gravei para a Rede Globo de Televisão uma entrevista sobre a almejada volta do Brasil ao Estado de Direito.

Em 8 de junho, uma grande alegria! Os bacharelandos de minha Faculdade me elegeram patrono de sua turma. À turma, os estudantes deram o nome "Senador Paulo Brossard" Para paraninfo, escolheram o professor Modesto de Souza Barros Carvalhosa.

No dia 12 de junho de 1977 . encontrei, surpreso, no Folhetim, caderno da Folha de $S$. Paulo, uma nota intitulada "O cravo retribuido" Estava assinada pela escritora Helena Silveira, a famosa cronista do jornal.

Rezava a nota:

"Certa feita, achava-me internada no hospital, aguardando uma intervenção cirúrgica. Não seria operação grave, mas de certa forma, eu estava 
preocupada diante do incógnito. Apreensiva, eu aguardava a enfermeira para apagar as luzes e me ajudar a passar a noite, a fim de enfrentar o dia seguinte. Foi quando ouvi baterem à porta. Surgiu, então, na entrada do quarto, o Prof. Goffredo, com um cravo vermelho na mão. Sem palavra, estendeu-me a flor. Levou um dedo aos lábios, indicando que eu não devia falar. Depois, saiu, tão silencioso como quando chegou. Saiu para a noite, estando feita sua dádiva de vida e esperança.

Hoje, anos passados, leio na imprensa as palavras altivas de meu amigo, pronunciadas sob as históricas Arcadas. A mocidade está presa a seu verbo. Ele aponta para o amanhã, um amanhã muito mais vasto do que o meu amanhã particular daquela noite de hospital.

Então, ainda comovida, meu Professor, quero retribuir-lhe o cravo.

Estendo-o por cima desta página do Folhetim. Inflamado, rubro, o cravo é um incêndio na ponta de meus dedos. Tome-o Professor. Ele é seu"

O dia 15 de junho de 1977, foi, para os estudantes de todo o Brasil, o Dia Nacional de Luto" Já o descrevi em outro depoimento.

As brutais violências praticadas, nesse dia, contra os estudantes e contra o edifício da Academia produziram em mim um sentimento de horror e revolta, que eu não sabia mais conter. Escrevi ao diretor da Faculdade uma cartadenúncia, datada de 21 de junho, relatando fatos por mim testemunhados, rogando imediatas providências da Congregação. Assinaram-na comigo os professores Dalmo de Abreu Dallari, Fábio Konder Comparato, Ignácio Botelho de Mesquita e Antonio Roberto Sampaio Dória.

Em 27 de junho, o deputado Alencar Furtado, do MDB, pronunciou um discurso intrépido. De seu texto integral, tomei conhecimento pelo ótimo noticiário do Jornal da Tarde, do dia $1^{\circ}$ de julho. "Que a nossa fala inicial" disse o parlamentar "seja uma homenagem aos companheiros que ficaram pelos caminhos da luta, injustiçados pelas cassações, pela suspensão de direitos, pela prisão ou pelo exílio. (...) É abominável o sistema em que a lei se torna instrumento do capricho dos dominadores. Nas autocracias, a lei existe para servir à força, e a força nem sempre existe para servir à lei. Desgraçadamente, acredita-se mais na força do que na lei. Mais no AI-5 do que no Poder Judiciário. (...) É insuportável, mais de uma década de arbítrio. O governo, fugindo da democracia, procura perpetuar-se no poder. (...) A legislação excepcional esbulhou o império da 
legalidade, elegendo o arbítrio. O regime abastardou a lei, vulnerou a intangibilidade do Judiciário, quebrantou o Legislativo, e colocou os dirigentes acima da Constituição, que, por sua vez, foi submetida aos caprichos dos Atos Institucionais. (...) O terror tornou-se árbitro do sistema. (...) O que queremos é a inviolabilidade dos direitos da pessoa humana, para que não haja lares em pranto, filhos órfãos de pais vivos, quem sabe mortos, talvez; órfãos do talvez ou do quem sabe. Para que não haja esposas que enviúvem com maridos vivos, quem sabe mortos, talvez; viúvas do talvez ou do quem sabe. (...) Há uma angústia nacional. Há uma ânsia de voltar a ser o que realmente somos. A vontade popular não pode mais ser represada, nem a liberdade ser condicionada pelo poder. Preparemo-nos, portanto, para lutar pela abertura democrática. A Nação como está não pode prosseguir. Chegou a hora de nós nos encontrarmos novamente. Este é o instante da libertação. Façamos um esforço comum pela Democracia. Não há quem resista aos apelos do povo. Não há quem desatenda aos clamores da Nação. Basta! Está é a hora do encontro nacional numa Assembléia Nacional Constituinte'

Em 30 de junho, num ambiente carregado de apreensões, a Congregação dos professores de minha Faculdade se reuniu, para debater a legalidade e o mérito do Pacote de Abril' conjunto de decretos autocráticos, baixados pelo ditador.

Nessa ocasião, procedi à leitura da carta-denúncia, que eu havia enviado ao diretor da Faculdade. Incontinenti, a Congregação aprovou, unanimemente, uma declaração de "repúdio às arbitrariedades da polícia, durante as concentrações estudantis"

Depois... naquela mesma sessão, seguiu-se um longo e árduo debate, sobre as reformas constitucionais, decretadas pelo general presidente da República... Afinal, de tudo quanto ali se discutiu, o que realmente ficou foi a decisão, tomada por maioria de votos, de que "a Congregação da Faculdade de Direito da USP não mais se reunirá para fixar posiçôes ante fatos de caráter político".

Lembro-me de que deixei, silenciosamente, a Sala da Congregação. Sai com o coração pesado. Fui ao Pátio, meu Pátio, meu jardim de pedra. Passeei lentamente por entre as Arcadas. Senti saudade, uma infinita saudade, do professor Braz Arruda. Acudiu-me à memória sua advertência sobre a missão histórica de nossa Academia. Não se esqueça!" recomendou ele. De pé, diante do Monumento dos Heróis, soltei para o céu um urro de desabafo. Percebi que dois estudantes, 
muito sérios, olhos esbugalhados, me fitavam. Pensaram, certamente, que o velho professor enlouquecera.

Mas, não. Eu não enlouquecera. Nessa mesma noite, atendi, depois do jantar, a diversos jornalistas. O Estado de S. Paulo, a Folha de S. Paulo, o Jornal do Brasil, todos, no dia seguinte, noticiaram minha carta e meu voto na Congregação. A Folha do dia 4 e o Estado do dia 6 voltaram ao mesmo assunto.

O que nós não sabíamos era que, naquele exato dia da Congregação 30 de junho de 1977 o general presidente da República cassara Alencar Furtado: cassara o mandato eletivo, e suspendera por dez anos os direitos políticos do líder da oposição no Brasil!

Ante a Nação estarrecida, o presidente chamou seus adversários de "demagogos, hipócritas, irresponsáveis, perturbadores da ordem, pregoeiros da discórdia, arautos da intriga, vivandeiros impenitentes, eternos cassandras, derrotistas e subversivos"

E, no dia 26 de julho, "considerando que as distorções das finalidades dos congressos e sessões públicas de que trata a Lei n. 5.682, de 21 de julho de 1971, resultaram em atos de contestação ao regime instituído pela Revolução de 31 de março de 1964; considerando que cabe ao presidente da República adotar as medidas necessárias à defesa da Revolução" o general presidente proibiu, pelo Ato Complementar n. 104, a promoção de congressos ou sessões públicas para a difusão dos programas de partidos, assim como a sua transmissão pelo rádio e televisão.

Então, o que vimos foi a reafirmação oficial de que toda contestação ao regime em vigor era definida como crime contra a ordem instituída. O que vimos, para nosso escândalo, foi que o general se promovera, definitivamente, a detentor do monopólio da ciência política e do civismo dos brasileiros.

Pois bem, nós queríamos proclamar nossa insurreição contra essa tutela, esse arbítrio.

Nós sabíamos que o que dá sentido ao desenvolvimento nacional, o que confere legitimidade às reformas sociais, o que dá autenticidade às renovações do Direito, são as livres manifestações do povo, nas urnas ou na praça pública, ou em seus órgãos de classe, nos diversos ambientes da vida.

Nós sustentávamos que quem devia planejar e propulsionar o desenvolvimento era o povo, ou os eleitos pelo povo o povo organizado, mas livre, 
porque ele é que era a fonte do Poder; ele é que tinha competência, mais do que ninguém, para defender seus interesses e seus direitos.

Sustentávamos que uma Nação desenvolvida era uma Nação que podia manifestar, e fazer sentir, a sua vontade. Era uma Nação com organização popular, com sindicatos autônomos, com sentros de debate, com partidos autênticos, com veículos de livre informação. Era uma Nação em que o povo escolhe seus dirigentes, e tem meios de introduzir sua vontade nas deliberações governamentais. Era uma Nação em que se acham abertos os amplos e francos canais de comunicação entre a sociedade civil e o Governo.

Não víamos que razões podiam existir para que comandantes das Forças Armadas continuassem a proferir ameaças contra civis, e a dizer, aos políticos e aos cidadãos em geral, como se deviam comportar. Não víamos o motivo pelo qual os militares, por mais ilustres que fossem, haveriam de ser considerados os melhores cidadãos do País. Que títulos ostentavam os militares para que pudessem ser tidos como a mais alta expressão da sabedoria política e do civismo? Além da força de suas armas, que possuíam eles para que lhes pudessem advir um Poder incontrastável?

Aliás, durante os longos treze anos de chumbo, o que presenciamos no Brasil foi o suceder ininterrupto de violências inauditas, praticadas pelas autoridades, contra pessoas e direitos.

Vimos eminentíssimos brasileiros serem vítimas de sanções arbitrárias. Vimos cientistas eméritos serem banidos, discricionariamente, de nossa Terra. Vimos punições serem aplicadas sem audiência dos acusados. Vimos seqüestros, torturas, assassinatos, praticados nas masmorras dos chamados órgãos de segurança. Vimos brasileiros desaparecerem da face da Terra, sem deixar vestígio do que lhes teria acontecido. Vimos o povo despojado do direito de escolher seus governantes, $\mathrm{e}$ assistimos ao fracasso de interventores e governantes nomeados. Vimos leigos elaborar charadas, que receberam o augusto nome de leis. Vimos o descalabro a que conduziram sucessivos e mirabolantes projetos, produzidos nas clausuras tecnocráticas da ditadura. Vimos improvisações apressadas causarem mal-estar e ruína, nas áreas da economia nacional. Vimos a inflação galopante flagelar o trabalhador, e ser tratada pelo ministro da Fazenda como "inflação pra xuxu" Vimos a corrupção desbragada proliferar livremente. Vimos o voto judicioso da oposição no Congresso Nacional ser acusado de exercício da "ditadura minoritária" Vimos um churrilho de mentiras, usado para justificar uma inapta reforma do Poder 
Judiciário. Vimos o Parlamento ser fechado, para permitir o enxerto atrabiliário de emendas na Constituição.

"Basta!" exclamou Alencar Furtado. Basta!, exclamávamos nós.

$\mathrm{O}$ que queriamos era ordem. $\mathrm{O}$ que queríamos era uma ordem que consagrasse o direito dos cidadãos de serem regidos por uma Constituição soberana, elaborada livremente pelos Representantes do Povo, numa Assembléia Nacional Constituinte; o direito de não ver ninguém jamais submetido a disposições de Atos do Poder Executivo, contrárias aos preceitos e ao espírito da Constituição; o direito de ter um Governo em que o Poder Legislativo e o Poder Judiciário possam cumprir sua missão com independência, sem medo de represálias e castigos do Poder Executivo; o direito de ter um Poder Executivo limitado pelas normas da Constituição soberana; o direito de escolher, em pleitos democráticos, seus governantes e legisladores; o direito de ser eleito governante ou legislador, e o de ocupar cargos na administração pública; o direito de se fazer ouvir pelos Poderes Públicos, e de introduzir seu pensamento nas decisões do Governo; o direito à liberdade justa, que é o direito de fazer ou de não-fazer o que a lei não proíbe; o direito à igualdade perante a lei, que é o direito de cada um de receber o que a cada um pertence; o direito à intimidade e à inviolabilidade do domicílio; o direito à propriedade honesta e o de conservá-la; o direito de organizar livremente sindicatos de trabalhadores, para que estes possam lutar em defesa de seus interesses; o direito à presunção de inocência, dos que não forem declarados culpados, em processo regular; o direito de imediata e ampla defesa dos que forem acusados de ter praticado ato ilícito; o direito de não ser preso, fora dos casos previstos em lei; o direito de não ser mantido preso, em regime de incomunicabilidade, fora dos casos da lei; o direito de não ser condenado a nenhuma pena que a lei não haja cominado antes do delito; o direito de nunca ser submetido à tortura, nem a tratamento desumano ou degradante; o direito de pedir a manifestação do Poder Judiciário, sempre que houver interesse legítimo de alguérn; o direito irrestrito de impetrar habeas corpus; o direito de ter juízes e tribunais independentes, com prerrogativas que os tornem refratários a injunções de qualquer ordem; o direito de ter uma imprensa livre; o direito de fruir das obras de arte e cultura, sem cortes ou restrições; o direito de exprimir o pensamento, sem qualquer censura, ressalvadas as penas legalmente previstas, para os crimes de calúnia, difamação e injúria; o direito de resposta; o direito de reunião e associação. 
Tais direitos são valores soberanos. São ideais que inspiram as ordenações jurídicas das nações verdadeiramente civilizadas. São princípios informadores do Estado de Direito.

Sim, o que queríamos era ordem. Mas a ordem que queríamos era a ordem do Estado de Direito.

A consciência jurídica do Brasil queria uma cousa só: o Estado de Direito já.

Foi numa noite de julho daquele ano de 1977. Foi numa ante-manhã de inverno. Era cedo, muito cedo, eu ainda não ouvira o relógio da sala bater as cinco horas. As pombas da alta-madrugada não haviam ainda chegado ao beiral de minha janela.

Silêncio no estúdio o grande silêncio fecundo, das horas que antecedem o nascer do dia.

Sentei-me à velha mesa, arredei livros, arredei papéis. Na minha frente, a folha branca, imaculada.

Senti o leve roçar da asa do Anjo na minha cabeça.

Peguei do lápis e, lentamente, escrevi no alto da página:

"Carta aos Brasileiros"

São Paulo, agosto de 1999. 